\title{
MarR-Family Transcription Factor HpaR Controls Expression of the vgrR-vgrS Operon of Xanthomonas campestris pv. campestris
}

\author{
Yue Pan, ${ }^{1,2}$ Fang Liang, ${ }^{3}$ Ru-Jiao Li, ${ }^{3}$ and Wei Qian ${ }^{1,+}$ \\ ${ }^{1}$ State Key Laboratory of Plant Genomics, Institute of Microbiology, Chinese Academy of Sciences, Beijing 100101, China; \\ ${ }^{2}$ School of Life Sciences, University of Chinese Academy of Sciences, Beijing 100049, China; and ${ }^{3}$ Beijing Institute of \\ Genomics, Chinese Academy of Sciences
}

Accepted 25 October 2017.

\begin{abstract}
MarR (multiple antibiotic resistance regulator)-family transcription factors (TFs), which regulate the expression of virulence factors and other physiological pathways in pathogenic bacteria, are regarded as ideal molecular targets for the development of novel antimicrobial strategies. In the plant bacterial pathogen Xanthomonas campestris pv. campestris, HpaR, a typical MarR-family TF, is associated with bacterial virulence, but its mechanism of virulence regulation remains unclear. Here, we dissected the HpaR regulon using high-throughput RNA sequencing and chromatin immunoprecipitation sequencing. HpaR directly or indirectly controls the expression of approximately 448 genes; it acts both as a transcriptional activator and a repressor to control the expression of downstream genes by directly binding to their promoter regions. The consensus HpaR-binding DNA motifs contain imperfect palindromic sequences similar to [G/T]CAACAATT[C/T]TTG. In-depth analysis revealed that HpaR positively modulates transcription level of the vgrR-vgrS operon that encodes an important two-component signal transduction system to sense iron depletion and regulate bacterial virulence. Epistasis analysis demonstrated that vgrR-vgrS is a core downstream component of $\mathrm{HpaR}$ regulation, as overexpression of $v g r R$ restored the phenotypic deficiencies caused by a hpaR mutation. This dissection of the HpaR regulon should facilitate future studies focused on the activating mechanism of HpaR during bacterial infection.
\end{abstract}

Xanthomonas campestris pv. campestris is a model organism for studying the disease pathogenesis of plant bacterial pathogens. A gram-negative bacterium belonging to class $\gamma$-Proteobacteria (Swings and Civetta 1993), this pathovar is the causative agent of black rot disease in cruciferous plants and was selected by plant pathologists as one of the "top 10" bacterial pathogens that are of scientific or economic importance (Mansfield et al. 2012). $X$. campestris pv. campestris invades hosts through stomata, wounds, and hydathodes and causes wilting, cankering, and distinctive "V"-shaped necrosis at plant leaf margins (Simpson and Johnson 1990). The genome of X. campestris pv. campestris, which comprises approximately 5.0 million base pairs (bp), encodes

\section{${ }^{\dagger}$ Corresponding author: Wei Qian; E-mail: qianw@im.ac.cn}

*The $\boldsymbol{e}$-Xtra logo stands for "electronic extra" and indicates that three supplementary figures and seven supplementary tables are published online.

(c) 2018 The American Phytopathological Society complex regulatory systems to control the expression of virulence factors and infectious processes (da Silva et al. 2002; Qian et al. 2005; Vorhölter et al. 2008). For example, a number of transcription factors (TFs) among the approximately $190 \mathrm{TFs}$ encoded by the bacterium have been found to control the expression of virulence factors or virulence-associated genes; these include four TFs belonging to the response regulators of twocomponent signal transduction systems (VgrR, PhoP, HrpG, and XerR/XibR), a CRP-like TF (Clp), an AraC-family TF (HrpX), a GntR-family TF (HpaR1), a LuxR-family TF (XccR), a Rrf2family TF (IscR), an OxyR-family TF (OxyR), a MerR-family TF (SoxR), two Fur-family TFs (Fur and Zur), and a MarR (multiple antibiotic resistance regulator)-family TF (HpaR). Inactivation of the aforementioned TF-coding genes results in remarkable virulence attenuation (Fuangthong et al. 2015; He et al. 2007; Huang et al. 2009; Ikawa and Tsuge 2016; Koebnik et al. 2006; Mahavihakanont et al. 2012; Mongkolsuk et al. 2000; Pandey et al. 2016; Peng et al. 2017; Su et al. 2016; Wang et al. 2011, 2016; Wei et al. 2007; Wengelnik et al. 1996). These TFs regulate various physiological processes in $X$. campestris pv. campestris, such as the expression of the type III secretion system, production of extracellular polysaccharides or enzymes, metal uptake, envelope stress responses, and cytogenesis, which suggests that bacterial virulence is tightly controlled by a complex network of TFs. To date, however, only the regulons of a limited number of these TFs, such as Clp, VgrR, PhoP, HrpG, and $\operatorname{HrpX}$, have been dissected in $X$. campestris pv. campestris by high-throughput transcriptomic methods. Investigation of the regulatory mechanisms of these virulence-associated TFs is needed to facilitate the development of novel antibacterial approaches to artificially manipulate these molecular targets.

MarR-family TFs regulate virulence in a diverse range of pathogenic bacteria (Grove 2013). These TFs control multiple cellular processes, including the production of virulence factors, response to antibiotic and oxidative stresses, and degradation of aromatic compounds (Ellison and Miller 2006). MarR-type TFs contain winged helix-turn-helix (wHTH) structures that directly bind double-stranded DNA (dsDNA) and modulate the transcription levels of genes (Hong et al. 2005). Small molecules, such as salicylates, metals, aromatic compounds, $p$-coumaroyl-CoA, and urate, are bound by the ligand-binding pocket of MarR-family TFs and modulate the DNA-binding activity of these proteins (Perera and Grove 2010). In X. campestris pv. campestris, HpaR (hypersensitive response and pathogenicity-associated regulator) was the first MarR-type TF found to regulate bacterial virulence. Disruption of this gene by transposon insertion was proved to significantly 
decrease virulence against its cabbage host (Qian et al. 2005). Subsequent analyses revealed that $h p a R$ controls production of extracellular proteases and the capacity to trigger a hypersensitive response (HR) in nonhost pepper (Wei et al. 2007). Inactivation of hpaR, however, did not affect production of exopolysaccharides, resistance to oxidative stress, or production of extracellular amylases and cellulases. In addition, the expression of $h p a R$ is subject to the control of $h r p G$ and $h r p X$, two other TFs that are important in the expression of the bacterial type III secretion system (Wei et al. 2007). cDNA-amplified fragment length polymorphism analysis of a close relative, $X$. campestris pv. vesicatoria, revealed that the messenger RNA (mRNA) level of a $h p a R$ ortholog was induced in a $h r p G-$ dependent manner when the bacterium was grown in a minimal medium (Noël et al. 2001). However, the HpaR regulon in bacterial species belonging to the genus Xanthomonas has never been investigated, and how this $\mathrm{TF}$ controls virulence factors and virulence-associated factors in X. campestris pv. campestris remains completely unknown.

In the present study, we used RNA sequencing (RNA-seq) and chromatin immunoprecipitation sequencing (ChIP-seq) to dissect the HpaR regulon. Our analysis revealed that HpaR acts as an activator or a repressor to modulate the expression of approximately 448 genes involved in a diverse set of physiological processes. The consensus HpaR-binding DNA motif was predicted and then experimentally verified by DNase I footprinting and an electrophoresis mobility shift assay (EMSA). Among the HpaR-regulated genes, we found that this TF binds directly to the promoter region of the $v g r R$-vgrS operon (Wang et al. 2016), which encodes a two-component signal transduction system (TCS) that senses iron-depleted environments and regulates bacterial virulence. Overexpression of $v g r R$ partially restored the virulence deficiency of the hpaR mutant and fully suppressed its protease overexpression and enhanced biofilm formation phenotypes. Our results demonstrate that HpaR is a global regulator of $X$. campestris pv. campestris. This TF controls the bacterial virulence through various pathways, including directly modulating the transcriptions of virulence factors and indirectly affecting virulence-associated factors by interacting with other regulators.

\section{RESULTS}

\section{Transcriptomic profiling \\ of $\boldsymbol{h p a R}$-regulated genes by RNA-seq.}

The hpaR gene (XC_2827) encodes a 166-amino acid (aa) TF that contains a wHTH DNA-binding motif (aa positions 52 to 111). Both protein secondary structure prediction by Pfam searching and construction of a three-dimensional structure by Phyre 2 modeling revealed that the protein is a well-matched MarR-family TF (confidence $>99.9 \%$ ) (Supplementary Fig. $\mathrm{S} 1)$. To investigate the HpaR regulon, RNA-seq analysis was used to screen for differentially expressed genes between a hpaR mutant and the wild-type (WT) strain of X. campestris pv. campestris 8004. A nonpolar, in-frame deletion mutant of hpaR $(\Delta \mathrm{hpaR})$ was constructed by the homologous, double-crossover recombination method (Supplementary Table S1). Bacterial cells were grown in rich nutrient-yeast-glycerol (NYG) medium and Xanthomonas virulence mimic 2 (XVM2) minimal medium that induces the expression of the type III secretion system (Schulte and Bonas 1992). Total RNAs were extracted from bacterial cells grown to the logarithmic phase (optical density at $600 \mathrm{~nm}\left[\mathrm{OD}_{600}\right]=0.4 \pm 0.01$ ). After synthesis of cDNA, adaptor ligation, polymerase chain reaction (PCR) amplification, and high-throughput sequencing, RNA-seq analysis revealed that 139 and 86 genes were upregulated (threshold $>1.5$-fold) in the hpaR mutant grown in NYG and
XVM2 media, respectively, while 94 and 72 genes were respectively downregulated when the bacterium was grown in these media (Fig. 1A to D, Supplementary Tables S3 and S4). A total of 39 genes, including four flagellar assembly genes ( $f \lg G$, $f l i H, f l i Q$, and a hook basal body protein-coding gene), were identified as differentially expressed under both growth conditions. Collectively, the expression levels of 352 nonredundant genes were impacted by the $h p a R$ deletion in our test regardless of growth conditions (Fig. 1A and B). These genes were classified into 10 functional categories, such as pathogenicity, metabolism of biomacromolecules, cell structure, and material transportation, which indicates that HpaR directly or indirectly regulates multiple physiological processes in $X$. campestris pv. campestris.

When $X$. campestris pv. campestris was grown in rich NYG medium, inactivation of $h p a R$ noticeably caused upregulation of virulence-associated genes encoding type II and III secretion systems, extracellular cellulase and pectate lyase, and flagellar assembly proteins, suggesting that HpaR directly or indirectly represses the expressions of these virulence-associated genes when the bacterium is grown in a nutrition-rich environment. Under XVM2 growth conditions, the hpaR mutation decreased the expression levels of genes responsible for lipopolysaccharide core synthesis, flagellar assembly, chemotaxis, and transportation, indicating HpaR positively controls the transcription of these virulence-associated genes. In addition, the hpaR mutation led to increases or decreases in the expressions of many regulatory genes, especially TCS genes and those encoding various TFs belonging to LysR, MerR, DeoR, LacI, and MarRfamilies, thus suggesting that HpaR plays an important role in complex regulatory networks.

\section{Identification of HpaR-regulated genes by ChIP-seq.}

RNA-seq analysis identifies genes regulated directly or indirectly by a TF. Consequently, ChIP-seq analysis is generally superior to RNA-seq for determining directly regulated genes because promoter regions coimmunoprecipitated with the TF are enriched during the analysis (Park 2009). To perform the ChIP assay, we constructed a strain of $X$. campestris pv. campestris (hpaR-his ${ }_{6}$ ) producing recombinant $\mathrm{HpaR}$ fused with a His $_{6}$ epitope tag at the C-terminal. Phenotypic profiling revealed that this genetic manipulation had no effect on bacterial virulence, production of extracellular proteases, amylases, and cellulases, or the ability to elicit a hypersensitive reaction in the nonhosts (Supplementary Fig. S2). This result indicates that the $\mathrm{His}_{6}$ tag had no marked negative impact on HpaR regulation. The recombinant strain was cultured in rich NYG and XVM2 minimal media. During ChIP, the DNA fragments of bacterial cells coimmunoprecipitated with HpaR using monoclonal anti-His ${ }_{6}$ antibody were enriched. Subsequent peak calling of the ChIP-seq data showed that HpaR was bound to the $5^{\prime}$ regions $(<200 \mathrm{bp})$ of 122 and 71 genes when $X$. campestris pv. campestris was grown under NYG and XVM2 conditions, respectively (Fig. 2A and B). There were, thus, 185 redundant genes whose promoter regions potentially bound to HpaR, eight of which were shared between bacterial samples under the two growth conditions. These 185 genes were classified into nine functional categories as shown in Supplementary Tables S5 and S6. Notably, the 5' promoter sequence of $h p a R$ was identified among these genes, which suggests that $\mathrm{HpaR}$ autoregulates its own transcription by binding to its own promoter.

Comparative analysis of ChIP-seq and RNA-seq data revealed that 89 genes $(48.1 \%)$ identified by ChIP-seq were also identified by RNA-seq. In the hpaR mutant, 34 and 12 ChIP-seq-identified genes were upregulated in NYG and XVM2 media, respectively, while 25 and 18 were correspondingly downregulated. These 
results suggest that HpaR acts either as an activator or a repressor depending on the regulated genes.

\section{HpaR regulates transcription of downstream genes by directly binding to their promoter regions.}

To investigate whether HpaR exerts its TF activity by binding to downstream gene promoter regions, we experimentally verified seven genes identified by RNA-seq and ChIP-seq analyses: XC_O136 (encoding a RhsD protein), XC_0141 ( $\alpha$-amylase), $X C \_0405$ (TonB-dependent receptor), XC_1057 (fimbrial assembly protein), $X C_{-} 1642$ ( $\alpha$-glucosidase), XC 2592 (also a RhsD protein), and hpaR (XC_2827) itself. The promoter regions of these genes contained sequences obtained by peak calling of the ChIP-seq data (Fig. 3A; Supplementary Fig. S3A). The corresponding DNA promoter sequences were amplified, and the PCR products (153 to $218 \mathrm{bp}$ ) were labeled with $\left[\gamma-{ }^{32} \mathrm{P}\right]$ ATP. Recombinant $\mathrm{HpaR}$ fused with a C-terminal $\mathrm{His}_{6}$ tag was obtained using an Escherichia coli BL21(DE3) expression system and was then purified by affinity chromatography. An EMSA revealed that HpaR bound to all seven DNA probes to form protein-DNA complexes (Fig. 3B to F). When unlabeled PCR probes were added to the reaction mixtures as competitors, the isotope signals representing the HpaRDNA complexes gradually decreased and the amount of free labeled DNA probes aggregating on the bottom of the nondenaturing polyacrylamide gels increased. These results demonstrate that these HpaR-DNA binding events were highly specific.

Based on the above results, quantitative real-time reverse transcription (qRT)-PCR was used to quantify mRNA levels of these seven genes in the hpaR mutant. As shown in Figure $3 \mathrm{G}$ to $\mathrm{K}$, when the bacterial strains grew in rich NYG medium, the mutation of $h p a R$ caused significant decreases in the mRNA levels of XC_O405 and XC_1057 to the levels of $47 \%$ and $45 \%$ compared with the WT strain but increased the expression level of $X C \_0141$ to $180 \%$ of the WT. It did not markedly affect the expression levels of $X C_{-}$0136, XC_1642, XC_2592, and hpaR itself. These results suggest that HpaR positively controls the expression of $X C_{-} 0405$ and $X C_{-} 1057$ under rich nutrition supply. When the bacterial strains were grown in XVM2 medium, however, the amounts of mRNA of $X C \_0136, X C \_1642$, $X C \_2592$, and $h p a R$ were significantly increased in the $h p a R$ mutant (ranging from 213 to $279 \%$ of the WT level), while the transcription levels of XC_0141, XC_0405, and XC_1057 remains unchanged. Genetic complementation of $h p a R$ by in trans provision of a full-length copy of hpaR in the mutant significantly restored gene-expression levels relative to those of WT strains (Fig. $3 \mathrm{G}$ to $\mathrm{K}$ ). These results support the idea that HpaR acted as a repressor to control transcription of the four genes (XC_0136, XC_1642, XC_2592, and hpaR) when $X$. campestris pv. campestris was grown in minimal medium. These observations also confirm that HpaR autoregulated its own transcription through a negative feedback loop when the bacterium was grown in XVM2 medium. Collectively, the above analyses experimentally demonstrate that HpaR has TF activity. The protein directly binds to the promoter region of downstream genes and modulates their transcription. In all the tested genes, including hpaR itself, HpaR acts as both activator and repressor to control their expression, which depends on the growth conditions of the bacterium.

\section{Dissection of the consensus HpaR-binding DNA motif.}

MEME analysis of potential binding DNA sequences obtained from the ChIP-seq data predicted two HpaR-binding motifs, which corresponded respectively to NYG and XVM2 growth conditions. As shown in Figure 2C, sequences of the two motifs were highly similar with slight variation. Under NYG medium, HpaR bound to a C[A/G][A/G]C[A/G][A/C] $[\mathrm{T} / \mathrm{G}][\mathrm{T} / \mathrm{G}][\mathrm{T} / \mathrm{C}] \mathrm{TTG}$-like motif, whereas a $[\mathrm{G} / \mathrm{T}] \mathrm{C}[\mathrm{A} / \mathrm{G}][\mathrm{A} / \mathrm{G}]$ $\mathrm{C}[\mathrm{A} / \mathrm{C}] \mathrm{A}[\mathrm{T} / \mathrm{G}][\mathrm{T} / \mathrm{G}] \mathrm{CTT}$-like motif was observed under the
A

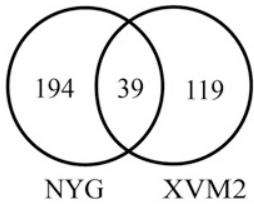

B

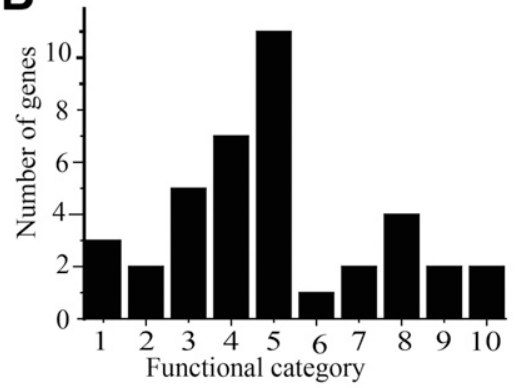

1. Biosynthesis of small molecules

2. Cell structure

3. Chemotaxis and mobility

4. Hypothetical proteins

5. Intermediary metabolism

6. Mobile genetic elements

7. Pathogenicity and HR

8. Protein metabolism

9. Regulatory function

10. Transport system
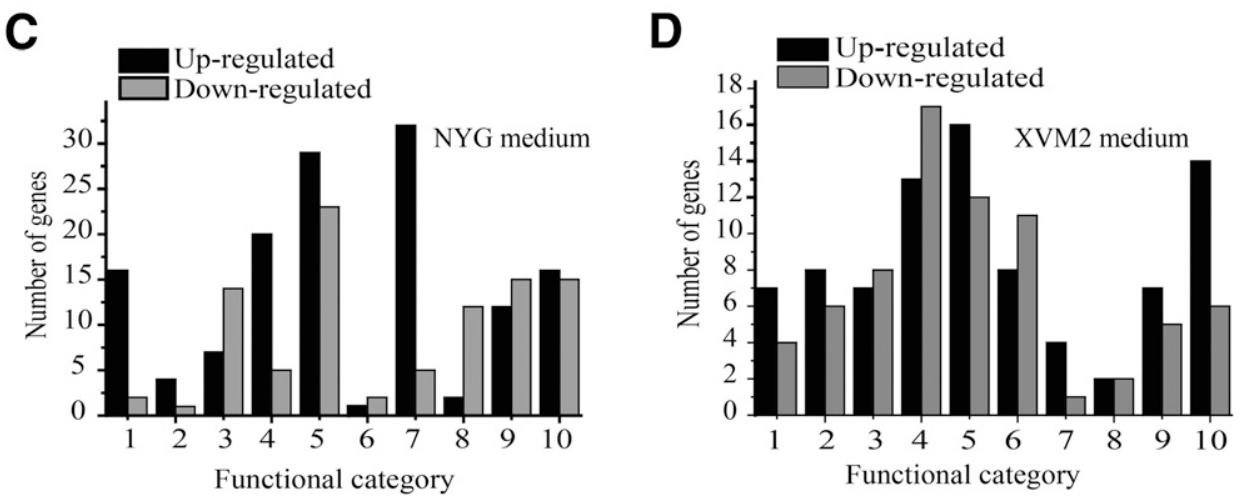

Fig. 1. Identification of differentially expressed genes associated with a mutation in hpaR. A, Venn diagram showing the number of differently expressed genes in the hpaR mutant compared with the wild-type (WT) strain grown in nutrient-yeast-glycerol (NYG) and Xanthomonas virulence mimic 2 (XVM2) media. B, Functional categories of nonredundant genes whose expressions were associated with the mutation in hpaR. Bacterial strains were grown in NYG or XVM2 media. C and D, Differentially expressed genes associated with the hpaR mutation. The number of up- and downregulated genes is shown. Functional categories are the same as in B. 
XVM2 condition. To experimentally verify the consensus binding motif, we selected the previously mentioned $X C_{-} 1642$ gene for in-depth analysis. $X C_{-} 1642$, which encodes an $\alpha$-glucosidase, was identified by $\overline{C h I P-s e q}$ analysis in a bacterial sample grown in XVM2 medium. According to RNA-seq analysis, the expression level of this gene was 1.5 to 2.5 times greater in the hpaR mutant compared with the WT strain. DNase I footprinting subsequently revealed that the HpaR protein protects two DNA regions (35 and $29 \mathrm{bp}$ in length) at the $5^{\prime}$ end of $X C_{-} 1642$ (Fig. 4A). As shown in Figure 4A, the two DNA regions contained the predicted HpaR-binding motif. We therefore chemically synthesized 40- and 35-bp doublestranded oligonucleotides based on the sequences of the two regions and labeled them with $\left[\gamma_{-}{ }^{32} \mathrm{P}\right]$ ATP. An EMSA using these two oligonucleotides as probes revealed that the purified HpaR protein directly bound to them (Fig. 4B and C). The binding events were specific, as addition of increasing concentrations of unlabeled DNA probes gradually caused the labeled probes to be out-competed (Fig. 4B and C) and led to a marked decrease in the isotope signals representing HpaRDNA complexes. To quantify HpaR-oligonucleotide binding affinity, the two oligonucleotides were subsequently end-labeled with 5' FAM (fluorescein) and were subjected to a microscale thermophoresis (MST) assay to determine disassociation constants between HpaR and probes. In this assay, HpaR bound to the two DNA probes with dissociation constant $\left(K_{\mathrm{d}}\right)$ values of $11.23 \pm 2.55$ and $66.34 \pm 2.62 \mu \mathrm{M}$, respectively, corresponding to intermediate to strong binding affinities (Fig. 4D and E). Taken together, these analyses confirmed the consensus DNA binding motifs of HpaR (Fig. 2C).

To theoretically predict the HpaR-binding site in the genome of $X$. campestris pv. campestris 8004, we used the consensus motif to screen for matching sequences within the $5^{\prime}$ promoter regions of all annotated genes in this genome. The results are listed in Supplementary Table S7. A total of 579 genes were identified as putatively regulated by $\mathrm{HpaR}$; this gene repertoire included $75(32 \%)$ and $55(30 \%)$ of the genes identified by RNA-seq and ChIP-seq, respectively.

HpaR controls the transcription of the vgrR-vgrS operon.

RNA-seq analysis showed that under NYG and XVM2 growth conditions, vgrR mRNA levels were decreased in the hpaR mutant. In addition, both ChIP-seq analysis and binding site prediction revealed that $\mathrm{HpaR}$ potentially binds to the $5^{\prime}$ promoter region of the $v g r R$-vgrS operon. These results suggest that HpaR regulates the transcription of $v g r R-v g r S$ operon. Our previous study showed that the bicistronic $v g r R$ - $v g r S$ operon encodes a TCS (Wang et al. 2016). VgrS is a membrane-bound

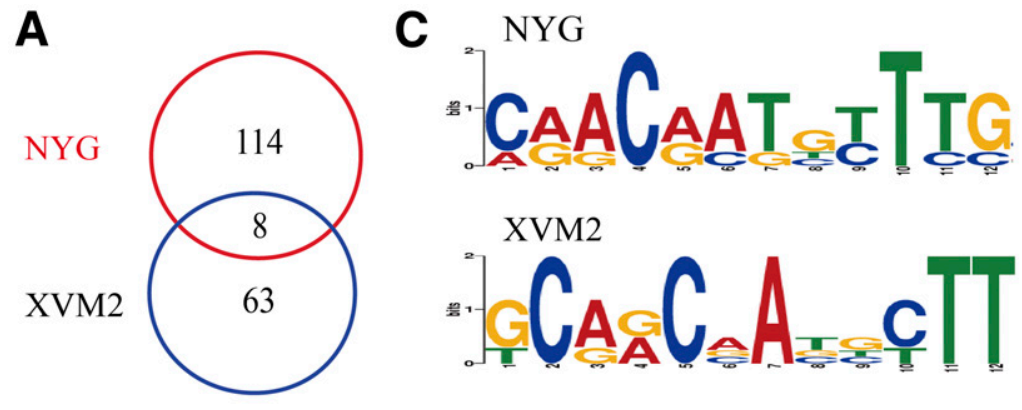

B

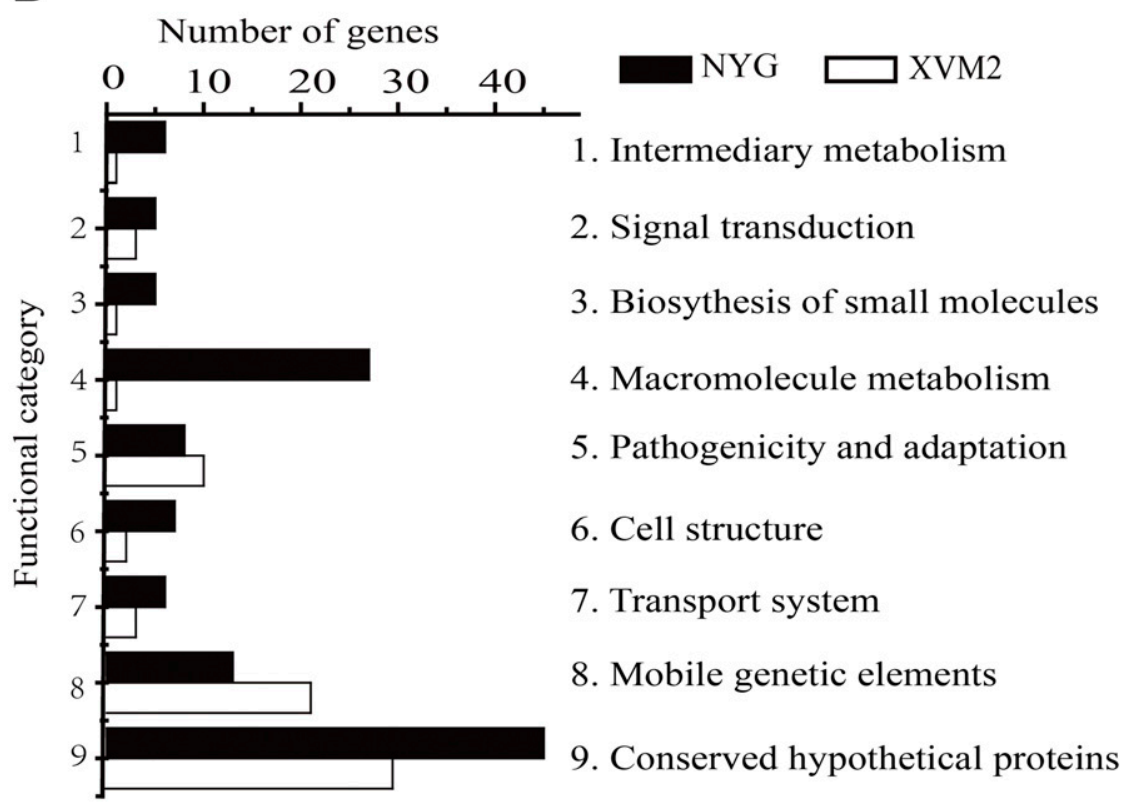

Fig. 2. Genome-wide analysis of the HpaR regulon by chromatin immunoprecipitation sequencing (ChIP-seq). A, Venn diagram showing the number of HpaRregulated genes and their ChIP-seq-identified promoters. Bacterial strains were grown in nutrient-yeast-glycerol (NYG) (red circle) and Xanthomonas virulence mimic 2 (XVM2) (blue circle) media. B, Functional categories of downstream genes potentially regulated by HpaR. Black and white columns represent the number of genes identified in bacterial cells grown in NYG and XVM2 media, respectively. C, Deduced consensus HpaR-binding DNA motifs based on ChIP-seq data and MEME analysis. WebLogo was used to illustrate the nucleotide composition. The height of each nucleotide is proportional to the level of conservation at that site. Upper and lower panels correspond to motifs predicted under NYG and XVM2 conditions, respectively. 
histidine kinase whose function is sensing of iron-depleted environments, while VgrR is a cytosolic response regulator that has TF activity. This TCS plays a critical role in regulating bacterial virulence and stress tolerance in $X$. campestris pv. campestris. In this previous study, we found that the promoter region of this operon is located in the $5^{\prime}$ region of $\operatorname{vgr} R(\mathrm{P} v g r R)$. Using a previously constructed PvgrR-GUS fusion reporter (Wang et al. 2016), we showed that $\beta$-glucuronidase (GUS) activity of the reporter in the hpaR mutant decreased to a level that was $37.7 \%$ of the WT strain (Fig. 5A). In addition, qRTPCR analyses revealed that $v g r R$ mRNA amounts significantly decreased, to levels respectively corresponding to 48.5 or $64.2 \%$ of the WT strain, when $X$. campestris pv. campestris was grown in XVM2 or NYG medium. In the genetic complementary strain ( $\Delta$ hpaR-hpaR), the expression of $v g r R$ was restored to the level of the WT strain (Fig. 5B and C). These results suggest that HpaR positively controls the transcription of $v g r R-v g r S$ operon.

To determine the possible interaction between HpaR and PvgrR, a 215-bp DNA fragment of PvgrR was amplified by PCR, was labeled with $\left[\gamma^{32} \mathrm{P}\right] \mathrm{ATP}$, and was used as a probe in an
EMSA. As shown in Figure 5D, HpaR recombinant protein bound to this DNA probe to form a clear HpaR-PvgrR complex. When an unlabeled probe of PvgrR was added to the EMSA reaction mixture, the isotopic signal of the HpaR-PvgrR complex gradually decreased to an undetectable level. In addition, an MST assay using a 5' FAM-labeled PvgrR DNA fragment found that the binding affinity of the HpaR-PvgrR interaction was $22.03 \pm 3.21 \mu \mathrm{M}$ (Fig. 5E), which suggests a relatively strong protein-DNA interaction. These results, therefore, demonstrate that HpaR physically binds to the promoter region of the $v g r R$-vgrS operon to positively regulate the transcription of these two important virulence regulatory genes.

\section{vgrR-vgrS is located downstream \\ of the HpaR regulatory cascade.}

The above analyses suggest that the vgrR-vgrS TCS is an important downstream regulator in the HpaR regulon for controlling physiological processes of $X$. campestris pv. campestris. To further investigate this regulatory relationship, we constructed a bacterial strain ( $\Delta$ hpaR-vgrR), in which $v g r R$ was overexpressed in the genetic background of the $h p a R$ mutant,
A $\begin{array}{cc}\text { PXC_0136: CCGATCAACAAGGCTTGACGAAGAAAATTTC } & -115 \\ -200 & -187 \\ \text { PXC_0141: CTCCGCAACGATTCTTGACCCTACACCCTAA } & -31 \\ -31 & -18 \\ \text { PXC_0405: TTGCGCCCACGGCGCTA TTCCCACCTGGAACC } & -39 \\ \text { PXC_1057: AGCATGAAGAAGCAGCC GATAGACCGGAACG } \\ -121 \\ \text { PhpaR: TCCCGCCGCAACATTGCTGACATGGGTAGCGC }\end{array}$

D

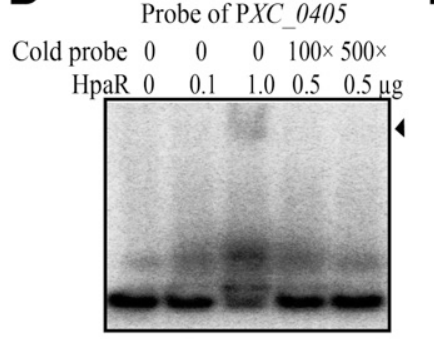

E Cold probe $\begin{array}{cccc}0 & 0 & 0 & 100 \times 500 \times\end{array}$

H

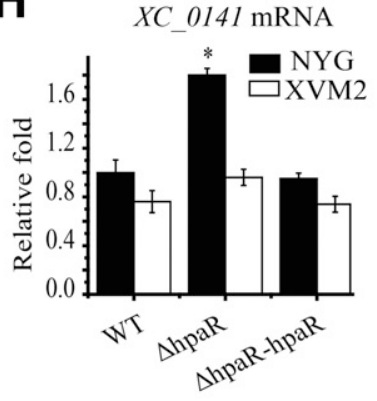

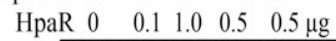

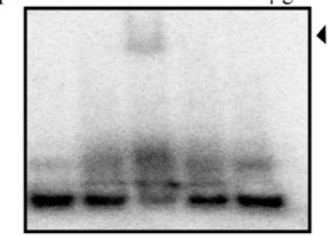

B

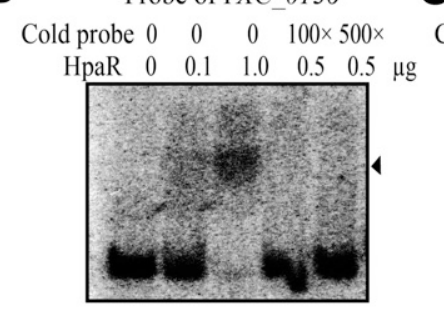

F

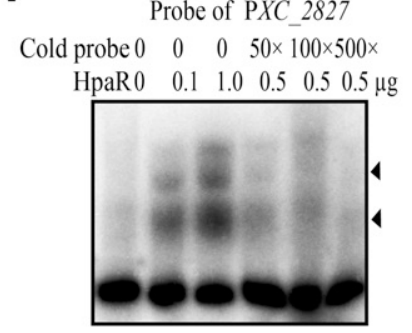

J

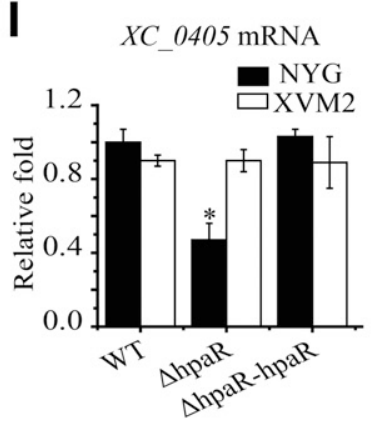

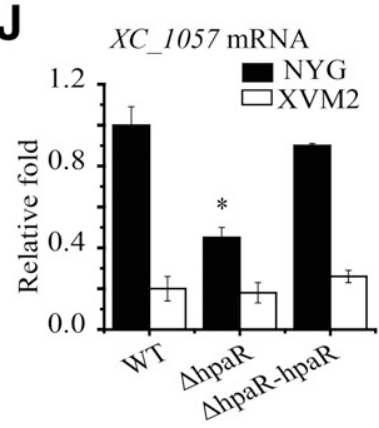

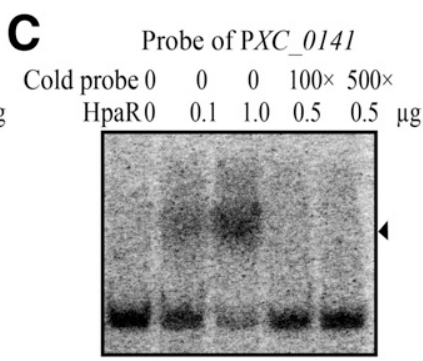

G

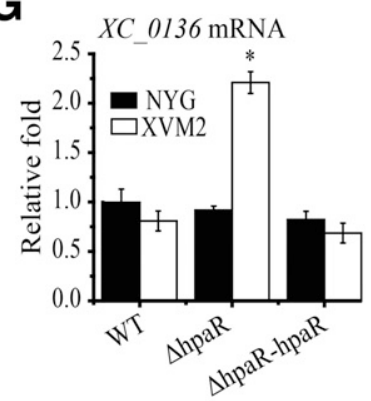

K

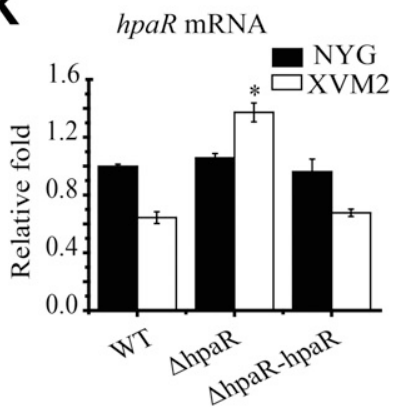

Fig. 3. Direct binding of HpaR to the promoter regions of downstream genes to control their expression. A, Sequences of the promoter regions of five genes. HpaR-binding sequences retrieved from peak calling of chromatin immunoprecipitation sequencing are highlighted by gray backgrounds. Sites of the potential binding motifs relative to the translational initiation sites were labeled. B to F, Direct binding of HpaR to the promoter regions of downstream genes. An electrophoresis mobility shift assay was used to determine the binding events between HpaR and DNA probes labeled with $\left[\gamma-{ }^{32} \mathrm{P}\right] \mathrm{ATP}$. Black triangles indicate HpaR-DNA complexes. Polymerase chain reaction (PCR) products of XC_0136, XC_0141, XC_0405, XC_1057, and $h p a R$ (XC_2827) promoter regions were used as probes. Increasing amounts of unlabeled probes (100- to 500-fold) were used as competitors. Each assay was repeated three times. $\mathbf{G}$ to $\mathbf{K}$, Quantification of messenger RNA (mRNA) of downstream genes in bacterial strains. Quantitative reverse transcription-PCR assays were used to quantify gene transcriptional levels. Transfer-messenger RNA cDNA was amplified as an internal control. Each assay was repeated independently three times, and only a representative is shown. Vertical bars indicate standard deviations $(n=3)$. An asterisk $(*)$ indicates a significant difference compared with the wild-type (WT) strain (Student's $t$ test, $P<0.05$ ). 
by in trans provision of a recombinant vector (pHM1::vgrR). After inoculating the bacterial strains onto the host cabbage (Brassica oleracea cv. Jingfeng No. 1), virulence capabilities of the $h p a R$ and $v g r R$ mutants almost completely disappeared (Fig. 6A) and the amounts of bacterial populations grown in planta significantly decreased (Fig. 6B). Overexpression of $v g r R$ in the hpaR mutant, however, partially restored bacterial virulence toward the WT strain (Fig. 6A). In addition, the size of the bacterial population grown in planta markedly increased, albeit at a lower level than that of the WT strain (Fig. 6B). We also constructed a strain in which $h p a R$ was overexpressed in the $\operatorname{vgr} R$ mutant. However, virulence and in planta growth assays revealed that overexpression of $h p a R$ did not change the phenotypes of the strain (Fig. 6A and B), thus indicating that hpaR is not located downstream of $v g r R$ regulation.
Regarding biofilm formation as quantified by crystal violet staining, inactivation of $h p a R$ resulted in a significant increase in biofilm quantity (Fig. 6C). In the $\Delta$ hpaR-vgrR strain, overexpression of $v g r R$ effectively suppressed the phenotypic change by decreasing the biofilm formation of the bacterium. As a previous study revealed, hpaR negatively regulates the production of extracellular proteases, we also checked this phenotypic alteration in recombinant strains. As shown in Figure 6D, deletion of hpaR caused a significant increase in extracellular protease production. In comparison, however, both genetic complementation of $h p a R$ as well as overexpression of $v g r R$ in the hpaR mutant caused extreme decreases in enzyme production. Meanwhile, overexpression of hpaR in the $\operatorname{vgr} R$ mutant $(\Delta v g r R-h p a R)$ did not change the phenocopied the biofilm formation and production of extracellular proteases of the

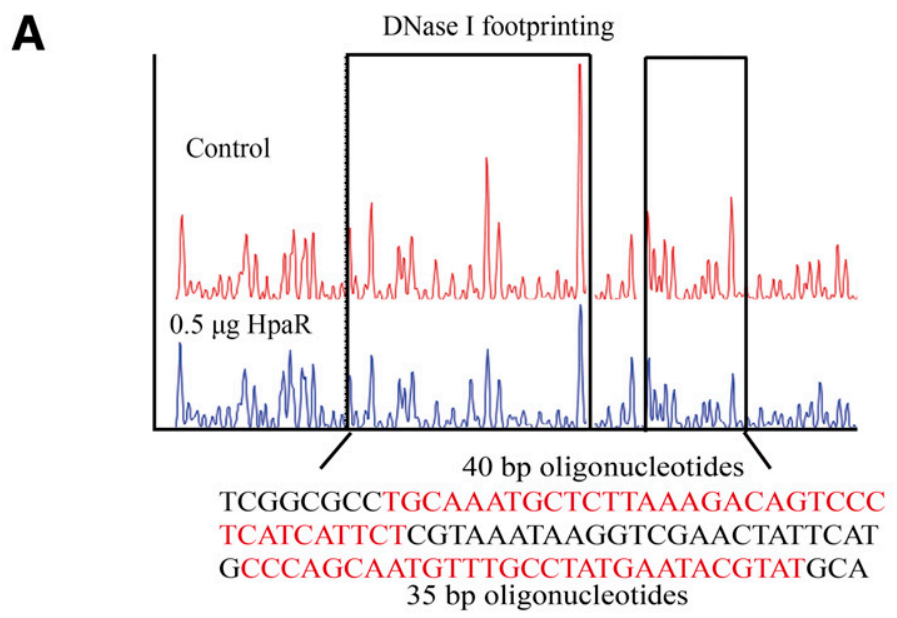

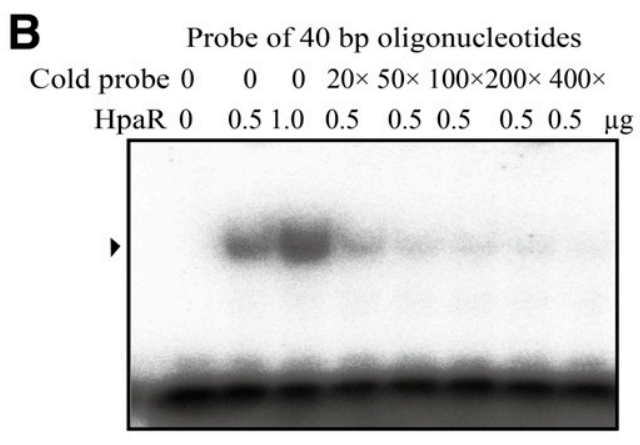

C Probe of 35 bp oligonucleotides

Cold probe $0 \quad 0 \quad 0 \quad 0 \quad 0 \quad 0 \quad 50 \times 80 \times 100 \times 200 \times$ $\begin{array}{lllllllllllll}\mathrm{HpaR} & 0 & 0.2 & 0.5 & 0.8 & 1.0 & 0.5 & 0.5 & 0.5 & 0.5 & \mu \mathrm{g}\end{array}$

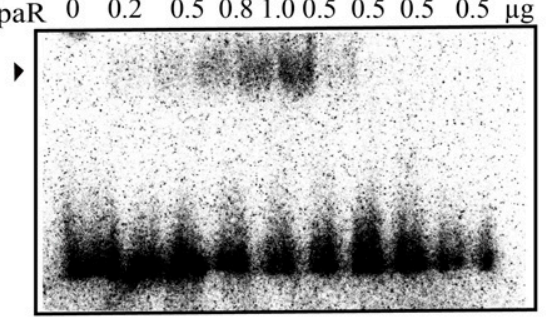

HpaR and 40 bp oligonucleotides

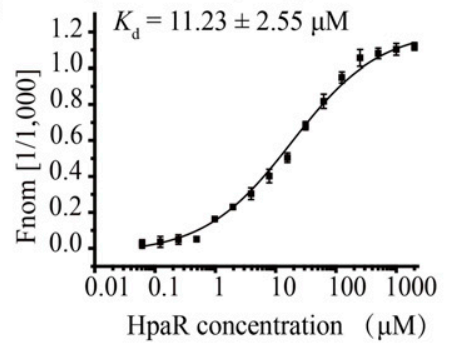

$\mathbf{E}$

$\mathrm{HpaR}$ and 35 bp oligonucleotides

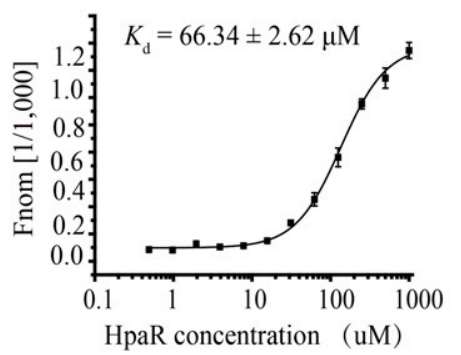

Fig. 4. Verification of the consensus HpaR-binding motif. A, Identification of HpaR-binding sites in XC_1642 promoter regions based on DNase I footprinting. The exact binding sequences of $X C_{-} 1642$ are highlighted in red. The control reaction is shown in the electropherogram at the top. The experiment was conducted using an autosequencer. $\mathbf{B}$ and $\mathbf{C}$, Direct binding of HpaR to chemically synthesized oligonucleotides. An electrophoresis mobility shift assay (EMSA) was used to determine the binding events between HpaR and DNA probes. Black triangles indicate HpaR-DNA complexes. Two oligonucleotides were synthesized, were end-labeled with $\left[\gamma-{ }^{32} \mathrm{P}\right] \mathrm{ATP}$, and were used as probes in the EMSA. Increasing amounts of unlabeled probes (20- to $200-$-fold) were used as competitors. Each assay was repeated three times. D and E, Quantification of HpaR-oligonucleotide binding affinity by microscale thermophoresis (MST). The oligonucleotides were labeled with $5^{\prime}$-fluorescein and incubated with the HpaR protein in an NT standard capillary in the MST assay. Titrations of the HpaR protein ranged from $50 \mathrm{nM}$ to $1 \mathrm{mM}$. The solid curve is the fit of the data points to the standard KD-Fit function. The black bars represent standard deviations $(n=3) . K_{\mathrm{d}}=$ dissociation constant. 
vgrR mutant $(\Delta \mathrm{vgrR})$. Collectively, these genetic results demonstrate that overexpression of $v g r R$ suppresses hpaR-induced phenotypic alterations in virulence, biofilm formation, and production of extracellular proteases and strongly support the notion that the VgrR-VgrS TCS is an essential regulator downstream of HpaR.

\section{DISCUSSION}

MarR-family TFs are widely distributed in bacteria and archaea. Each bacterial genome has been estimated to encode an average of seven such TFs (Perera and Grove 2010). Previous studies have revealed that MarR-family TFs regulate the virulence of many pathogenic bacteria of animals and plants. Examples include SlyA of Salmonella enterica (Dolan et al. 2011), Rv1404 of Mycobacterium tuberculosis (Healy et al. 2016), PecS of Dickeya dadantii (Praillet et al. 1996), SarZ of Staphylococcus aureus (Kaito et al. 2006), and RovA of Yersinia pestis (Cathelyn et al. 2006). The genome of $X$. campestris pv. campestris encodes approximately 10 MarR-family TFs, but only the function of HpaR has been experimentally investigated. In the close relative $X$. campestris pv. phaseoli, another MarR-family TF, OhrR, has been found to sense peroxide and modulate oxidative stress responses (Klomsiri et al. 2005; Panmanee et al. 2002). The ortholog of OhrR in $X$. campestris pv. campestris 8004 is $X C \_0273$, whose function remains unknown. In the present study, we dissected the regulon of HpaR, using RNA-seq and ChIP-seq analyses. According to our results, HpaR directly or indirectly controls the transcription levels of hundreds of genes, some of which participate in bacterial virulence and elicitation of HR in host plants (Figs. 1 and 2). Based on these analyses, HpaR-binding consensus motifs containing the imperfect palindromic sequences were predicted and experimentally verified (Figs. 2 and 4). HpaR has TF activity to directly bind the promoter regions of downstream genes and acts both as a repressor and an activator to control gene transcription (Fig. 3). Among these promoter regions, we found that HpaR binds to cis-regulatory elements in the $5^{\prime}$ upstream region of the $v g r R$ - $v g r S$ operon and positively controls its transcription (Fig. 5), thereby playing an important role in bacterial virulence and stress responses (Fig. 6). This dissection of the HpaR regulon should facilitate in-depth study of the molecular mechanism underlying transcriptional networks of $X$. campestris pv. campestris.

Our study revealed that HpaR controls the bacterial virulence of $X$. campestris pv. campestris through various regulatory pathways. First, HpaR directly binds to the promoter regions of a limited number of genes encoding virulence-associated factors to modulate their transcription; these genes include type IV secretion system genes and genes encoding the type IV pili assembly, RhsD proteins, ABC transporters, and TonBdependent receptors for iron uptake (Fig. 3). Second, HpaR controls expression levels of regulatory genes that are critical for virulence. ChIP-seq and RNA-seq analyses revealed that the expression of many genes encoding other TFs, two-component signaling proteins, and alternative sigma factors, were down- or up-regulated in the hpaR mutant, and we have provided genetic and biochemical evidence to demonstrate that HpaR activates the transcription of the $v g r R-v g r S$ operon (Figs. 5 and 6). VgrR$\mathrm{VgrS}$ is one of the TCSs involved in regulating virulence and
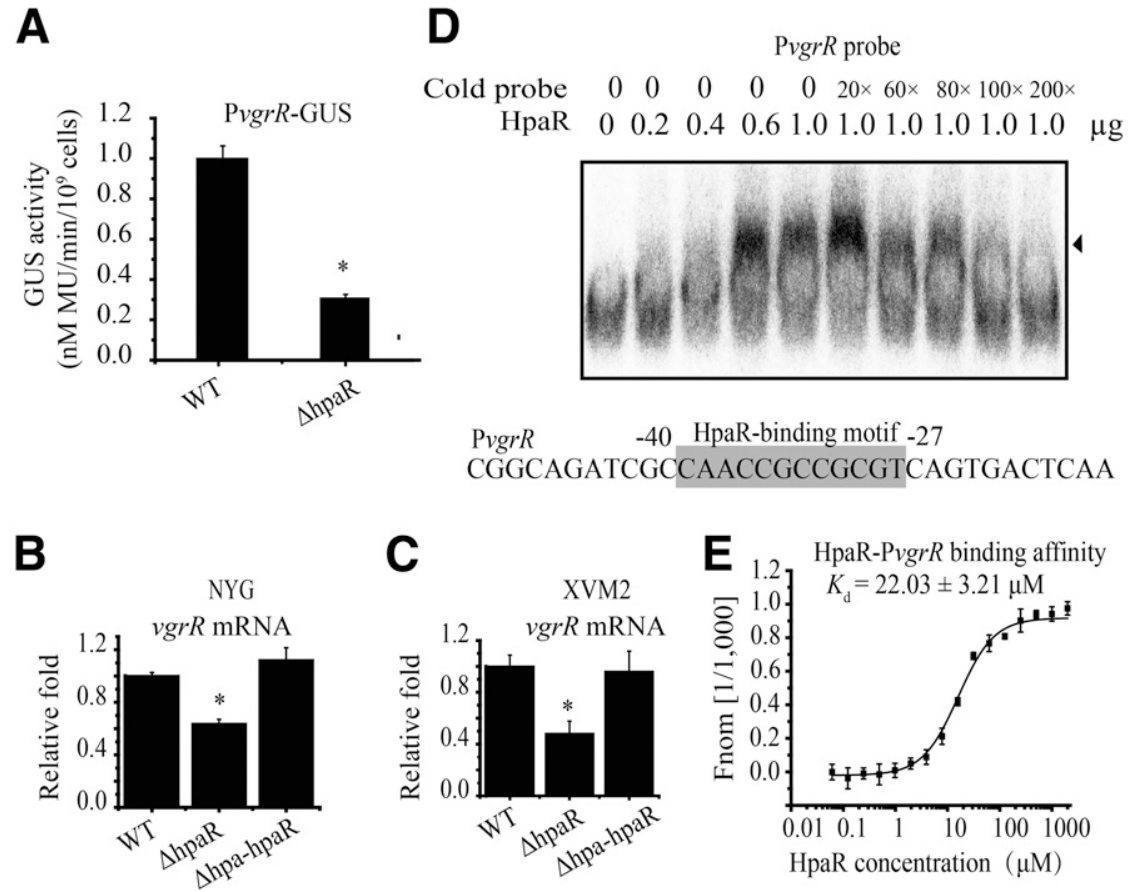

Fig. 5. Binding of HpaR to the promoter region of the $v g r R$-vgrS operon to positively control its transcription. A, Quantification of the promoter activity of the vgrR-vgrS operon by a GUS activity assay. A recombinant vector (pHM2::PvgrR-GUS) was provided in trans to bacterial strains for the GUS activity assay B-C, Messenger RNA (mRNA) levels of $v g r R$ in bacterial strains. Quantitative reverse transcription-polymerase chain reaction (qRT-PCR) assays were used to quantify the amount of $v g r R$ mRNA in different bacterial strains. Transfer-messenger RNA RNA cDNA was used as an internal control. Each assay was repeated independently three times, and only a representative is shown. In $\mathrm{A}, \mathrm{B}$, and $\mathrm{C}$, vertical bars indicate standard deviations $(n=3)$. $*$ indicates a significant difference compared with the wild-type (WT) strain (Student's $t$ test, $P<0.05$ ). D, Direct binding of HpaR to the PvgrR promoter region. The black triangle indicates the HpaR-DNA complex. PCR products of the $v g r R$ promoter region were labeled with $\left[\gamma_{-}{ }^{32} \mathrm{P}\right] \mathrm{ATP}$ and used as probes. The sequence of the HpaR-binding motif and its location relative to the translational initiation site is shown at the bottom of the figure. Increasing amounts of unlabeled probes were used as competitors. Each assay was repeated three times. E, Quantification of HpaR-PvgrR binding affinity by an MST assay. The PCR products of the $v g r R$ promoter region were labeled with $5^{\prime}$-fluorescein $(45 \mathrm{nM})$ and were incubated with HpaR in an NT standard capillary for the MST assay. $K_{\mathrm{d}}=$ dissociation constant. The black bars represent standard deviations $(n=3)$. 
stress responses of $X$. campestris pv. campestris (Wang et al. 2016). In an iron-depleted environment, such as in host tissues, the autokinase activity of $\mathrm{VgrS}$ is maintained at a high level. The phosphorylated VgrS then transfers a phosphoryl group onto VgrR to activate the latter's TF activity. In due course, VgrR modulates the expression of downstream genes associated with virulence and stress responses (Wang et al. 2016). As shown in Figure 6, overexpression of $\operatorname{vgrR}$ partially but significantly restored the deficiency in virulence caused by the $h p a R$ deletion, strongly implying that $v g r R-v g r S$ is downstream of the HpaR regulation. Third, HpaR indirectly affects the expressions of many virulence-associated genes. For example, RNA-seq analysis retrieved six promoter sequences of flagellar assembly genes, including $f l g F, f l i J, f l g G$, and $f l g B$. The $5^{\prime}$ upstream sequences of these genes contained no HpaR-binding motifs, which suggests they are not directly regulated by HpaR. Flagella contribute to the motility and chemotaxis of bacterial cells. The role of flagella in virulence as well as a pathogen-associated molecular pattern has been reported in various pathogenic bacteria, including X. campestris pv. campestris (Gómez-Gómez and Boller 2000; Haiko and Westerlund-Wikström 2013; Lee et al. 2003). Furthermore, many virulence-associated genes, including those encoding the type III secretion system, TonB-dependent receptors for iron uptake, and extracellular enzymes such as pectate lyase, were indirectly modulated by HpaR, as these genes identified by RNA-seq had no HpaR-binding motifs as cis-regulatory elements.
Collectively, these results support the idea that HpaR is a pleiotropic regulator controlling the level of virulence of $X$. campestris pv. campestris.

Although MarR-family TFs usually act as transcriptional repressors in the regulation of downstream genes (Grove 2013), they can also behave as transcriptional activators (Perera and Grove 2010). This dual functionality is applicable to HpaR regulation. As shown in Figure 3, HpaR repressed the transcription levels of five tested genes, including $h p a R$ itself, under NYG or XVM2 growth conditions. Inactivation of hpaR resulted in upregulation of these genes under certain circumstances. Notably, the binding sites of HpaR in the promoter regions of these genes were located $100 \mathrm{bp}$ upstream of the translational initiation sites. When the bacterium was grown in NYG or XVM2 medium, however, HpaR positively regulated the transcription of the $X C_{-} 0405, X C_{-}$1057, and vgrR-vgrS operon, as the amount of their mRNAs significantly decreased in the hpaR mutants. In contrast to the above five genes, the binding site of HpaR to PXC_0405, PXC_1057, and PvgrR are all around the -35 regions of these genes (Fig. 5). As has been shown in previous studies, the general DNA binding mechanism of MarR-family TFs is highly conserved, and the position of their cis-regulatory elements determines whether the TFs function as activators or repressors. In regard to activation of gene transcription, for example, the TF OhrR of Streptomyces coelicolar binds to the -35 region of the ohrA gene and
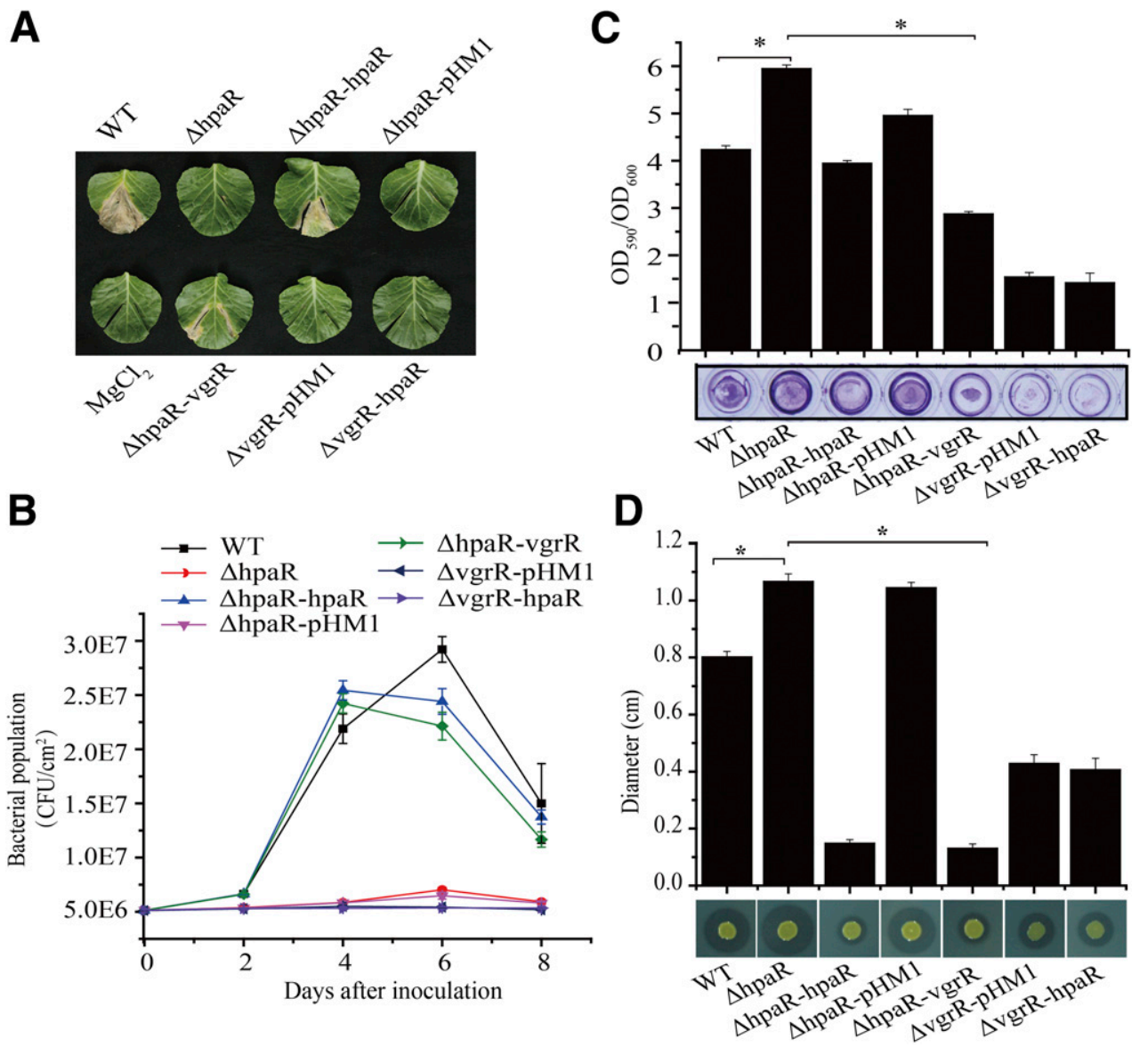

Fig. 6. Results of epistasis analyses revealing that $v g r R$ is a downstream modulator of HpaR regulation. A, Overexpression of $v g r R$ partially restoring the virulence deficiency caused by the hpaR mutation. Bacterial strains were inoculated onto host cabbage (Brassica oleracea cv. Jingfeng No. 1), with 10 mM $\mathrm{MgCl}_{2}$ used as a negative control. Virulence levels were recorded 10 days after inoculation. B, Plant growth assay of bacterial strains. Bacterial strains were injected into plant leaves using a 1-ml syringe. Bacterial colonies were isolated from leaf disks and were counted by serial dilution after inoculation. Each value shown is the average number calculated from six leaf disks. C, Quantification of biofilm formation of bacterial strains. Biofilms were stained with crystal violet and were measured by optical density $(\mathrm{OD})$ absorbance $\left(\mathrm{OD}_{590} / \mathrm{OD}_{600}\right)$. D, Assay of extracellular protease production. Error bars represent standard deviation $(n=6)$. An asterisk $(*)$ indicates $P<0.05$, calculated by Student's $t$ test. 
interacts with RNA polymerase to activate the transcription (Oh et al. 2007), while release of transcriptional repression by interaction with a repressor, such as nucleoid-like proteins (H-NS), has been reported for the TF RovA of Yersinia pseudotuberculosis (Heroven et al. 2004). As for transcriptional repression, MarR-family TFs have been found to distort promoter-DNA topology (Deochand et al. 2016), interfere with RNA polymerase binding by promoter occlusion (Stapleton et al. 2002), and hinder mRNA elongation by transcriptional collision (Galán et al. 2003). Consequently, the biochemical basis of how HpaR activates or represses downstream gene expression, especially in the context of stochastic change of environments, is an open question to be investigated.

In addition to TF activity for binding dsDNA, MarR-family TFs can bind small molecules to modulate their DNA-binding behavior (Grove 2013). MarR-family TFs are, therefore, also intracellular sensors for detecting environmental cues, with ligand binding one of the central mechanisms to activate these TFs. Unlike LysR- or LuxR-family TFs that contain ligandbinding domains separate from DNA-binding domains, however, MarR-family TFs have no such domains and, instead, bind small chemicals via their ligand-binding pockets (Perera and Grove 2010). In E. coli, for example, $\mathrm{Cu}^{2+}$ oxidizes the cysteine residues of MarR to generate disulphide bonds between MarR dimers, which results in the dissociation of MarR from its binding DNA. This process releases the repression of MarR on the transcription of downstream genes responsive to antibiotic treatment (Hao et al. 2014). In Staphylococcus epidermidis, sodium salicylate and antibiotics such as $\beta$-lactam and aminoglycosides interact with the MarR-family TF TcaR to antagonize the DNA-binding activity of TcaR, which triggers bacterial biofilm formation to resist these antibiotics (Chang et al. 2010). In the present study, our preliminary MST assay excluded the possibility that HpaR binds to salicylates with a mediate affinity (data not shown). In addition, sequence alignment indicated that the primary sequence of HpaR has little similarity to the other MarR-family TFs whose three-dimensional protein structures were dissected. Ligand binding by HpaR, if present, thus remains completely unelucidated. Future study is needed to investigate the activating mechanism of $\mathrm{HpaR}$ as a TF during infection, including the identification of small molecules possibly binding to this important virulence regulator of $X$. campestris pv. campestris.

\section{MATERIALS AND METHODS}

Bacterial strains, plasmids, and growth conditions.

Xanthomonas campestris pv. campestris strains were routinely cultivated at $28^{\circ} \mathrm{C}$ in rich NYG medium (per liter, $5 \mathrm{~g}$ of tryptone, $3 \mathrm{~g}$ of yeast extract, and $20 \mathrm{~g}$ of glycerol, $\mathrm{pH}$ 7.0) and minimal XVM2 medium (per liter, $5 \mathrm{~g}$ of glucose, $1.0 \mathrm{~g}$ of sodium citrate, $2 \mathrm{~g}$ of $\left(\mathrm{NH}_{4}\right)_{2} \mathrm{SO}_{4}, 4 \mathrm{~g}$ of $\mathrm{K}_{2} \mathrm{HPO}_{4}, 6 \mathrm{~g}$ of $\mathrm{KH}_{2} \mathrm{PO}_{4}$, and $0.2 \mathrm{~g}$ of $\mathrm{MgSO}_{4}, \mathrm{pH}$ 7.0). E. coli strains were grown aerobically at $37^{\circ} \mathrm{C}$ in Luria-Bertani medium. Antibiotics were added as necessary at the following concentrations: rifampicin $(25 \mu \mathrm{g} / \mathrm{ml})$, spectinomycin $(150 \mu \mathrm{g} / \mathrm{ml})$, and kanamycin $(50 \mu \mathrm{g} / \mathrm{ml})$. Xanthomonas campestris pv. campestris 8004 electro-competent cells were prepared by washing bacterial cells at the exponential phase three times with $10 \%$ ice-cold glycerol.

\section{Bacterial genetic manipulation and epistasis analysis.}

Construction of in-frame deletion mutants was based on the homologous double-crossover method, using the suicide vector pK18mobSacB according to previous studies (Bürckstümmer et al. 2006; Wang et al. 2016). Genetic complementation or overexpression of genes was performed by constructing recombinant
pHM1 vectors, which were inserted in trans into corresponding bacterial strains. All primer sequences used in this study are listed in Supplementary Table S2.

To determine the epistastic relationship between $h p a R$ and $v g r R$, a full-length $v g r R$ gene was overexpressed in the $h p a R$ in-frame deletion mutant or vice versa, by providing a recombinant $\mathrm{pHM} 1$ vector (pHM1::vgrR or $\mathrm{pHM1::hpaR).} \mathrm{In} \mathrm{this} \mathrm{vector,}$ vgrR or hpaR is subject to the control of a PlacZ promoter. The recombinant strains were employed for phenotypic characterization.

\section{Phenotypic characterization of bacterial strains.}

Extracellular enzyme assays and plant inoculation was carried out according to a previous report (Qian et al. 2008). In brief, strains of $X$. campestris pv. campestris were cultivated to nearly $10^{6} \mathrm{CFU}$ per milliliter and were then inoculated onto susceptible, 8-week-old cabbage plants (Brassica oleracea cv. Jingfeng No. 1) by clipping the leaf tips with presterilized scissors dipped into the bacterial cultures. Lesions were measured and photographed at 10 days after inoculation. For inplanta growth assays, bacterial populations of each strain were determined on six inoculated leaves every $48 \mathrm{~h}$. After grinding each harvested leaf in $10 \mathrm{mM} \mathrm{MgCl}_{2}$, the leaf homogenate was serially diluted and was plated onto NYG plates. Bacterial numbers were counted after incubation at $28^{\circ} \mathrm{C}$ for $48 \mathrm{~h}$. Each assay was independently repeated three times, and bacterial populations of each strain were calculated as average values from eight inoculated leaves at each time point.

\section{qRT-PCR analyses.}

Total bacterial RNA was extracted from bacterial strains at the exponential growth phase $\left(\mathrm{OD}_{600}=0.4 \pm 0.05\right)$, using Trizol reagent (Invitrogen, Waltham, MA U.S.A.) according to the manufacturer's instructions. After measuring RNA concentrations with a NanoDrop 1000 spectrophotometer (Thermo Scientific, Wilmington, DE, U.S.A.), DNA contamination was removed by digestion with RNase-free DNase I (Ambion, Austin, TX, U.S.A.). cDNA was synthesized using random primers (Promega, Madison, WI, U.S.A.) and Superscript III reverse transcription (Invitrogen). mRNA levels of target genes were quantified by qRT-PCR using Maxima SYBR green (Fermentas, Waltham, MA, U.S.A.) in a DNA Engine Opticon 2 system (Bio-Rad, Hercules, CA, U.S.A.), according to the manufacturer's instructions. cDNA of transfer-messenger RNA was amplified as an internal control. Each qRT-PCR experiment was typically repeated independently three times, with three technical repeats per sample. One representative of each set of biological repeats was selected and reported.

\section{High-throughput RNA-seq.}

Bacterial strains were cultured in minimal NYG or XVM2 medium overnight to $\mathrm{OD}_{600} \mathrm{~nm}=0.4$, and then, cells were collected by centrifugation before total RNA extraction. The mRNA was enriched by removing $16 \mathrm{~S}$ and $23 \mathrm{~S}$ rRNAs with a MICROBEnrich kit (Ambion). The RNA libraries for sequencing were prepared using TruSeq RNA kits (Illumina, San Diego, CA, U.S.A.), and RNA-seq was performed by Illumina HiSeqTM 2000. All clean reads were aligned to the complete genomic sequence of $X$. campestris pv. campestris 8004 with SOAPaligner/SOAP2. The number of clean reads aligning to each genomic position on each DNA strand was calculated. The total numbers of reads aligning to each functional category and each putative gene were calculated. Analysis of differentially expressed genes was performed using normalized RPKMO values (reads per kilobasepair of gene per million reads aligning to annotated open reading frames) by CLC Genomic Workbench for RNA-seq (CLC Bio, Aarhus, Denmark). the 
differential expression analyses were performed in $R$ version 3.1.1 using the DESeq2 package. $P$ values were adjusted by the default method in DESeq2 and genes were considered differentially expressed when adjusted $P$ values below 0.05 were obtained. The 1.5-fold threshold was set as a core data set.

\section{GUS reporter activity assays.}

To construct a promoter-GUS transcriptional fusion, DNA sequences corresponding to the promoter of $\operatorname{vgrR}$-vgrS were amplified and ligated to the gusA gene, with the ShineDalgarno sequence of gusA acting as the ribosome-binding site. The inserts were ligated into vector pHM2 and were transformed into bacterial strains. For GUS activity assays, bacterial cells were collected by centrifugation and were stored immediately in liquid nitrogen. Cells were resuspended in $1 \times$ GUS extraction buffer $(50 \mathrm{mM}$ sodium phosphate, $\mathrm{pH} 7.0,5 \mathrm{mM}$ dithiothreitol [DTT], and $1 \mathrm{mM}$ EDTA, pH 8.0), were lysed by sonication, and were centrifuged, with the supernatants used for GUS activity assays. GUS activity was measured by the fluorometric method using 4-methylumbelliferyl $\beta$-D-glucuronide (4-MUG) (Goldbio, St. Louis) as the substrate. A standard curve was established by diluting 4-MUG (Sigma) stock solution. The fluorescence of samples and standard curve solutions was measured using an excitation wavelength of $360 \mathrm{~nm}$ and an emission wavelength of $460 \mathrm{~nm}$.

\section{Protein expression, purification, and extraction.}

A prokaryotic expression system with vector pET30a and E. coli BL21 (DE3) (Novagen, Darmstadt, Germany) was used to express recombinant $\mathrm{HpaR}$ fused with a C-terminal $\mathrm{His}_{6}$ epitope. Protein was expressed and purified by affinity chromatography using Ni-NTA agarose beads (Novagen), according to the manufacturer's manual. In brief, $E$. coli strains were grown to an $\mathrm{OD}_{600}$ of 0.6 and were then induced with $0.5 \mathrm{mM}$ isopropyl- $\beta$-D-thiogalactoside for $18 \mathrm{~h}$ at $16^{\circ} \mathrm{C}$. The bacteria were collected by centrifugation and were treated with lysis buffer (50 mM Tris-HCl, pH 7.5; $0.5 \mathrm{M} \mathrm{NaCl} ; 10 \%$ glycerol; $0.1 \%$ Triton X-100; and $1 \mathrm{mM}$ phenylmethylsulfonyl fluoride [PMSF]). Buffers used for protein purification with Ni-NTA beads (Novagen) were as follows: Ni-NTA binding buffer (300 mM NaCl; $50 \mathrm{mM}$ sodium phosphate buffer, $\mathrm{pH}$ 7.0; and $10 \mathrm{mM}$ imidazole, $\mathrm{pH} 8.0)$, Ni-NTA washing buffer $(300 \mathrm{mM}$ $\mathrm{NaCl}, 50 \mathrm{mM}$ sodium phosphate buffer, $\mathrm{pH} 7.0$; and $30 \mathrm{mM}$ imidazole, $\mathrm{pH}$ 8.0) and Ni-NTA elution buffer $(300 \mathrm{mM} \mathrm{NaCl}$, $50 \mathrm{mM}$ sodium phosphate buffer, $\mathrm{pH} 7.0$; and $10 \mathrm{mM}$ imidazole, $\mathrm{pH}$ 8.0). Purified $\mathrm{His}_{6}$-tagged proteins were dissolved in storage buffer $(50 \mathrm{mM}$ Tris-HCl, $\mathrm{pH} 8.0 ; 0.5 \mathrm{mM}$ EDTA; $50 \mathrm{mM} \mathrm{NaCl}$; and $5 \%$ glycerol).

\section{EMSAs.}

To detect HpaR-DNA binding, PCR products of the corresponding promoter region or chemically synthesized dsDNA probe were labeled with $\left[\gamma-{ }^{32} \mathrm{P}\right] \mathrm{ATP}$ using T4 polynucleotide kinase (NEB) and were purified using a ProbeQuant G-50 column (GE Healthcare). Binding reactions were carried out in $20-\mu \mathrm{l}$ volumes of reaction buffer $(10 \mathrm{mM}$ Tris- $\mathrm{HCl}, \mathrm{pH} 7.5$; $50 \mathrm{mM} \mathrm{KCl} ; 1 \mathrm{mM}$ DTT; and $1 \mu \mathrm{l}$ of $50 \mathrm{ng} / \mu \mathrm{l}$ poly[dI:dC]). Labeled DNA probe ( 2 to $4 \mathrm{fmol}$ ) and 2 to $6 \mu \mathrm{M}$ HpaR were used in each EMSA. For the competition reaction, a certain amount of unlabeled DNA probe was co-incubated for $20 \mathrm{~min}$ at room temperature before electrophoresis. Prior to electrophoresis, $4 \mu \mathrm{l}$ of DNA loading buffer $(0.25 \%$ bromophenol and $80 \%$ glycerol) was added to stop the EMSA reaction. The samples were then loaded onto a 5\% native polyacrylamide gel electrophoresis gel. Prior to autoradiography, electrophoresis was performed at $120 \mathrm{~V}$ for about $40 \mathrm{~min}$ in $0.5 \times$ Tris-borate-
EDTA buffer. Cold probes (not isotope-labeled) were also used in the competitive experiments.

\section{ChIP-seq.}

ChIP was performed according to a previous study (Wang et al. 2014). Briefly, bacterial strains were grown in NYG and XVM2 media until the $\mathrm{OD}_{600}$ reached $0.4 \pm 0.05$. Bacterial cells were collected by centrifugation, were cross-linked with $1 \%$ formaldehyde, and were subsequently quenched with $0.5 \mathrm{M}$ glycine for $10 \mathrm{~min}$. The cells were re-collected by centrifugation, were washed in $10 \mathrm{ml}$ of cold Tris-buffered saline $(150 \mathrm{mM} \mathrm{NaCl}$ and $20 \mathrm{mM}$ Tris- $\mathrm{HCl}, \mathrm{pH} 7.5)$, and were resuspended in $1 \mathrm{ml}$ of lysis buffer $(10 \mathrm{mM}$ Tris, $\mathrm{pH} \mathrm{8.0;20 \%}$ sucrose; $50 \mathrm{mM} \mathrm{NaCl} ; 10 \mathrm{mM}$ EDTA; and $10 \mathrm{mg}$ of lysozyme per milliliter). IP buffer (50 mM HEPES-KOH, $\mathrm{pH} 7.5$; $150 \mathrm{mM} \mathrm{NaCl} ; 1 \mathrm{mM}$ EDTA; $1 \%$ Triton-X 100; 0.1\% sodium deoxycholate; $0.1 \%$ sodium dodecyl sulfate [SDS]; and $1 \mathrm{mM}$ PMSF) was added to the bacterial cell suspension, and the cells were sonicated, using a Diagenode Bioruptor (Diagenode, Liege, Belgium), to generate DNA fragments of about 100 to $500 \mathrm{bp}$. After centrifugation, the solution was precleared with $20 \mu \mathrm{l}$ of protein A sepharose, at $4^{\circ} \mathrm{C}$ for $10 \mathrm{~min}$ on a slow rotator, and a $100-\mu \mathrm{l}$ aliquot was retained as the loading control DNA (input sample). For the ChIP assays, $50 \mu \mathrm{l}$ of protein A sepharose (50\% slurry) and $2 \mu \mathrm{l}$ of an anti-His ${ }_{6}$ antibody were added to an 800- $\mu \mathrm{l}$ aliquot of the DNA sample and the mixture was incubated at $4^{\circ} \mathrm{C}$ overnight, with slow rotation. The beads were collected by centrifugation and were washed with IP buffer and wash buffer $(10 \mathrm{mM}$ Tris- $\mathrm{HCl}, \mathrm{pH} 8.0 ; 250 \mathrm{mM}$ $\mathrm{LiCl} ; 1 \mathrm{mM}$ EDTA; $0.5 \%$ NP40 [equivalent to Triton X-100]; and $0.5 \%$ sodium deoxycholate). The immunoprecipitated chromatin was removed from the beads by adding $100 \mu \mathrm{l}$ of elution buffer (50 mM Tris, $\mathrm{pH} 7.5 ; 10 \mathrm{mM}$ EDTA; and 1\% SDS), and the solution was incubated for $10 \mathrm{~min}$ at $65^{\circ} \mathrm{C}$. RNase $A$ and proteinase $\mathrm{K}$ were used to remove RNA and protein, respectively. The DNA was purified by PCR purification sequencing on an Illumina Highseq-2000 system by BGI (Beijing). The resulting high-throughput sequencing reads were analyzed by the Burrows-Wheeler aligner method. The cleaned reads were aligned to the genomic sequence of $X$. campestris pv. campestris 8004. Peak calling was conducted with MACS2 (Zhang et al. 2008). The consensus HpaR-binding motif analysis was completed using the MEME and FIMO tools in the MEME software suite (Bailey et al. 2015).

\section{DNase I footprinting assay.}

A DNase I footprinting assay was performed to determine the HpaR-binding sites on the promoter region of $v g r R$. For preparation of fluorescent FAM-labeled probes, the promoter region of $X_{-} C_{-} 1642$ was PCR-amplified with Dpx DNA polymerase (TOLO Biotech, Shanghai, China) from the 1,642-probe T plasmid, using primers M13F-47 (FAM) and M13R-48. The FAM-labeled probes were purified using a Wizard SV gel and PCR clean-up system (Promega, Madison, WI, U.S.A.) and were quantified on a NanoDrop 2000C instrument (Thermo Scientific). DNase I footprinting assays were performed similarly to those reported by Stock et al. (2000). For each assay, 400 -ng probes were incubated with different amounts of HpaR protein in a total volume of $40 \mu \mathrm{l}$. After incubation for $30 \mathrm{~min}$ at $25^{\circ} \mathrm{C}, 10 \mu \mathrm{l}$ of a solution containing approximately 0.015 units of DNase I (Promega) and $100 \mathrm{nmol}$ of freshly prepared $\mathrm{CaCl}_{2}$ was added, with incubation then continued for $1 \mathrm{~min}$ at $25^{\circ} \mathrm{C}$. The reaction was stopped by adding $140 \mu$ of DNase I stop solution $(200 \mathrm{mM}$ unbuffered sodium acetate, $30 \mathrm{mM}$ EDTA, and 0.15\% SDS). Samples were extracted with phenol/ chloroform, were precipitated with ethanol, and the pellets were dissolved in $30 \mu \mathrm{lminiQ}$ water. Preparation of the DNA 
ladder, electrophoresis, and data analysis were as described previously (Stock et al. 2000), except that a GeneScan-LIZ500 size standard (Applied Biosystems, Foster City, CA, U.S.A.) was used.

\section{MST measurement.}

MST was used to quantify HpaR-DNA binding affinities. Oligonucleotide primers (50 bp) for target genes, labeled with 5 '-FAM, were synthesized by Invitrogen and were annealed to an unlabeled complementary primer to form dsDNA. The labeled dsDNA was added to serially diluted protein reaction volumes (at an initial concentration of $40 \mu \mathrm{M}$ ) containing $50 \mathrm{mM}$ Tris- $\mathrm{HCl}$ (pH 7.4), $150 \mathrm{mM} \mathrm{NaCl}, 10 \mathrm{mM} \mathrm{MgCl}_{2}$, and $0.05 \%$ (vol/vol) Tween-20. The KD fit function of NanoTemper analysis software version 1.5.41 was used for curve fitting and calculation of the $K_{\mathrm{d}}$ value.

\section{ACKNOWLEDGMENTS}

The authors thank members of our laboratory for helpful comments. This work was supported by the Ministry of Science and Technology of China (grant number 2016YFD0100602), the National Natural Science Foundation (grant numbers 31370127, 31671989, and 31400071), the Strategic Priority Research Program of the Chinese Academy of Sciences (grant number XDB11040700), and the State Key Laboratory of Plant Genomics.

\section{LITERATURE CITED}

Bailey, T. L., Johnson, J., Grant, C. E., and Noble, W. S. 2015. The MEME suite. Nucleic Acids Res. 43 (W1):W39-W49.

Bürckstümmer, T., Bennett, K. L., Preradovic, A., Schütze, G., Hantschel, O., Superti-Furga, G., and Bauch, A. 2006. An efficient tandem affinity purification procedure for interaction proteomics in mammalian cells. Nat. Methods 3:1013-1019.

Cathelyn, J. S., Crosby, S. D., Lathem, W. W., Goldman, W. E., and Miller, V. L. 2006. RovA, a global regulator of Yersinia pestis, specifically required for bubonic plague. Proc. Natl. Acad. Sci. U.S.A. 103:13514 13519.

Chang, Y. M., Jeng, W. Y., Ko, T. P., Yeh, Y. J., Chen, C. K. M., and Wang, A. H. J. 2010. Structural study of TcaR and its complexes with multiple antibiotics from Staphylococcus epidermidis. Proc. Natl. Acad. Sci. U.S.A. 107:8617-8622.

da Silva, A. C. R., Ferro, J. A., Reinach, F. C., Farah, C. S., Furlan, L. R., Quaggio, R. B., Monteiro-Vitorello, C. B., Van Sluys, M. A., Almeida, N. F., Alves, L. M. C., do Amaral, A. M., Bertolini, M. C., Camargo, L. E. A., Camarotte, G., Cannavan, F., Cardozo, J., Chambergo, F., Ciapina, L. P., Cicarelli, R. M. B., Coutinho, L. L., Cursino-Santos, J. R., El-Dorry, H., Faria, J. B., Ferreira, A. J. S., Ferreira, R. C. C., Ferro, M. I. T., Formighieri, E. F., Franco, M. C., Greggio, C. C., Gruber, A., Katsuyama, A. M., Kishi, L. T., Leite, R. P., Lemos, E. G. M., Lemos, M. V. F., Locali, E. C., Machado, M. A., Madeira, A. M. B. N., MartinezRossi, N. M., Martins, E. C., Meidanis, J., Menck, C. F. M., Miyaki, C. Y., Moon, D. H., Moreira, L. M., Novo, M. T. M., Okura, V. K., Oliveira, M. C., Oliveira, V. R., Pereira, H. A., Rossi, A., Sena, J. A. D., Silva, C., de Souza, R. F., Spinola, L. A. F., Takita, M. A., Tamura, R. E., Teixeira, E. C., Tezza, R. I. D., Trindade dos Santos, M., Truffi, D., Tsai, S. M., White, F. F., Setubal, J. C., and Kitajima, J. P. 2002. Comparison of the genomes of two Xanthomonas pathogens with differing host specificities. Nature 417:459-463.

Deochand, D. K., Meariman, J. K., and Grove, A. 2016. pH-dependent DNA distortion and repression of gene expression by Pectobacterium atrosepticum PecS. ACS Chem. Biol. 11:2049-2056.

Dolan, K. T., Duguid, E. M., and He, C. 2011. Crystal structures of SlyA protein, a master virulence regulator of Salmonella, in free and DNAbound states. J. Biol. Chem. 286:22178-22185.

Ellison, D. W., and Miller, V. L. 2006. Regulation of virulence by members of the MarR/SlyA family. Curr. Opin. Microbiol. 9:153-159.

Fuangthong, M., Jittawuttipoka, T., Wisitkamol, R., Romsang, A., Duangnkern, J., Vattanaviboon, P., and Mongkolsuk, S. 2015. IscR plays a role in oxidative stress resistance and pathogenicity of a plant pathogen, Xanthomonas campestris. Microbiol. Res. 170:139-146.

Galán, B., Kolb, A., Sanz, J. M., García, J. L., and Prieto, M. A. 2003. Molecular determinants of the hpa regulatory system of Escherichia coli: The HpaR repressor. Nucleic Acids Res. 31:6598-6609.
Gómez-Gómez, L., and Boller, T. 2000. FLS2: An LRR receptor-like kinase involved in the perception of the bacterial elicitor flagellin in Arabidopsis. Mol. Cell 5:1003-1011.

Grove, A. 2013. MarR family transcription factors. Curr. Biol. 23: R142-R143.

Haiko, J., and Westerlund-Wikström, B. 2013. The role of the bacterial flagellum in adhesion and virulence. Biology (Basel) 2:1242-1267.

Hao, Z., Lou, H., Zhu, R., Zhu, J., Zhang, D., Zhao, B. S., Zeng, S., Chen, X., Chan, J., He, C., and Chen, P. R. 2014. The multiple antibiotic resistance regulator MarR is a copper sensor in Escherichia coli. Nat. Chem. Biol. 10:21-28.

He, Y. W., Ng, A. Y. J., Xu, M., Lin, K., Wang, L. H., Dong, Y. H., and Zhang, L. H. 2007. Xanthomonas campestris cell-cell communication involves a putative nucleotide receptor protein Clp and a hierarchical signalling network. Mol. Microbiol. 64:281-292.

Healy, C., Golby, P., MacHugh, D. E., and Gordon, S. V. 2016. The MarR family transcription factor Rv1404 coordinates adaptation of Mycobacterium tuberculosis to acid stress via controlled expression of Rv1405c, a virulence-associated methyltransferase. Tuberculosis (Edinb.) 97 154-162.

Heroven, A. K., Nagel, G., Tran, H. J., Parr, S., and Dersch, P. 2004. RovA is autoregulated and antagonizes H-NS-mediated silencing of invasin and rovA expression in Yersinia pseudotuberculosis. Mol. Microbiol. 53: 871-888.

Hong, M., Fuangthong, M., Helmann, J. D., and Brennan, R. G. 2005. Structure of an OhrR-ohrA operator complex reveals the DNA binding mechanism of the MarR family. Mol. Cell 20:131-141.

Huang, D. L., Tang, D. J., Liao, Q., Li, X. Q., He, Y. Q., Feng, J. X., Jiang, B. L., Lu, G. T., and Tang, J. L. 2009. The Zur of Xanthomonas campestris is involved in hypersensitive response and positively regulates the expression of the hrp cluster via $h r p X$ but not $h r p G$. Mol. PlantMicrobe Interact. 22:321-329.

Ikawa, Y., and Tsuge, S. 2016. The quantitative regulation of the hrp regulator $\mathrm{HrpX}$ is involved in sugar-source-dependent hrp gene expression in Xanthomonas oryzae pv. oryzae. FEMS Microbiol. Lett. 363:fnw071.

Kaito, C., Morishita, D., Matsumoto, Y., Kurokawa, K., and Sekimizu, K. 2006. Novel DNA binding protein SarZ contributes to virulence in Staphylococcus aureus. Mol. Microbiol. 62:1601-1617.

Klomsiri, C., Panmanee, W., Dharmsthiti, S., Vattanaviboon, P., and Mongkolsuk, S. 2005. Novel roles of ohrR-ohr in Xanthomonas sensing, metabolism, and physiological adaptive response to lipid hydroperoxide. J. Bacteriol. 187:3277-3281.

Koebnik, R., Krüger, A., Thieme, F., Urban, A., and Bonas, U. 2006. Specific binding of the Xanthomonas campestris pv. vesicatoria AraCtype transcriptional activator $\mathrm{HrpX}$ to plant-inducible promoter boxes. J. Bacteriol. 188:7652-7660.

Lee, M. C., Weng, S. F., and Tseng, Y. H. 2003. Flagellin gene fliC of Xanthomonas campestris is upregulated by transcription factor Clp. Biochem. Biophys. Res. Commun. 307:647-652.

Mahavihakanont, A., Charoenlap, N., Namchaiw, P., Eiamphungporn, W., Chattrakarn, S., Vattanaviboon, P., and Mongkolsuk, S. 2012. Novel roles of SoxR, a transcriptional regulator from Xanthomonas campestris, in sensing redox-cycling drugs and regulating a protective gene that have overall implications for bacterial stress physiology and virulence on a host plant. J. Bacteriol. 194:209-217.

Mansfield, J., Genin, S., Magori, S., Citovsky, V., Sriariyanum, M., Ronald, P., Dow, M., Verdier, V., Beer, S. V., Machado, M. A., Toth, I., Salmond, G., and Foster, G. D. 2012. Top 10 plant pathogenic bacteria in molecular plant pathology. Mol. Plant Pathol. 13:614-629.

Mongkolsuk, S., Whangsuk, W., Fuangthong, M., and Loprasert, S. 2000. Mutations in $\operatorname{oxy} R$ resulting in peroxide resistance in Xanthomonas campestris. J. Bacteriol. 182:3846-3849.

Noël, L., Thieme, F., Nennstiel, D., and Bonas, U. 2001. cDNA-AFLP analysis unravels a genome-wide $h r p G$-regulon in the plant pathogen Xanthomonas campestris pv. vesicatoria. Mol. Microbiol. 41:12711281.

Oh, S. Y., Shin, J. H., and Roe, J. H. 2007. Dual role of OhrR as a repressor and an activator in response to organic hydroperoxides in Streptomyces coelicolor. J. Bacteriol. 189:6284-6292.

Pandey, S. S., Patnana, P. K., Lomada, S. K., Tomar, A., and Chatterjee, S. 2016. Co-regulation of iron metabolism and virulence associated functions by iron and XibR, a novel iron binding transcription factor, in the plant pathogen Xanthomonas. PLoS Pathog. 12:e1006019.

Panmanee, W., Vattanaviboon, P., Eiamphungporn, W., Whangsuk, W., Sallabhan, R., and Mongkolsuk, S. 2002. OhrR, a transcription repressor that senses and responds to changes in organic peroxide levels in Xanthomonas campestris pv. phaseoli. Mol. Microbiol. 45:1647-1654. 
Park, P. J. 2009. ChIP-seq: Advantages and challenges of a maturing technology. Nat. Rev. Genet. 10:669-680.

Peng, B. Y., Pan, Y., Li, R. J., Wei, J. W., Liang, F., Wang, L., Wang, F. F., and Qian, W. 2017. An essential regulatory system originating from polygenic transcriptional rewiring of PhoP-PhoQ of Xanthomonas campestris. Genetics 206:2207-2223.

Perera, I. C., and Grove, A. 2010. Molecular mechanisms of ligandmediated attenuation of DNA binding by MarR family transcriptional regulators. J. Mol. Cell Biol. 2:243-254.

Praillet, T., Nasser, W., Robert-Baudouy, J., and Reverchon, S. 1996. Purification and functional characterization of $\mathrm{PecS}$, a regulator of virulence-factor synthesis in Erwinia chrysanthemi. Mol. Microbiol. 20: 391-402.

Qian, W., Han, Z. J., Tao, J., and He, C. 2008. Genome-scale mutagenesis and phenotypic characterization of two-component signal transduction systems in Xanthomonas campestris pv. campestris ATCC 33913. Mol. Plant-Microbe Interact. 21:1128-1138.

Qian, W., Jia, Y., Ren, S. X., He, Y. Q., Feng, J. X., Lu, L. F., Sun, Q., Ying, G., Tang, D. J., Tang, H., Wu, W., Hao, P., Wang, L., Jiang, B. L., Zeng, S., Gu, W. Y., Lu, G., Rong, L., Tian, Y., Yao, Z., Fu, G., Chen, B., Fang, R., Qiang, B., Chen, Z., Zhao, G. P., Tang, J. L., and He, C. 2005. Comparative and functional genomic analyses of the pathogenicity of phytopathogen Xanthomonas campestris pv. campestris. Genome Res. 15:757-767.

Schulte, R., and Bonas, U. 1992. Expression of the Xanthomonas campestris pv. vesicatoria hrp gene cluster, which determines pathogenicity and hypersensitivity on pepper and tomato, is plant inducible. J. Bacteriol. 174:815-823.

Simpson, R. B., and Johnson, L. J. 1990. Arabidopsis thaliana as a host for Xanthomonas campestris pv campestris. Mol. Plant-Microbe Interact. 3: 233-237.

Stapleton, M. R., Norte, V. A., Read, R. C., and Green, J. 2002. Interaction of the Salmonella typhimurium transcription and virulence factor SlyA with target DNA and identification of members of the SlyA regulon. J. Biol. Chem. 277:17630-17637.

Stock, A. M., Robinson, V. L., and Goudreau, P. N. 2000. Two-component signal transduction. Annu. Rev. Biochem. 69:183-215.
Su, H. Z., Wu, L., Qi, Y. H., Liu, G. F., Lu, G. T., and Tang, J. L. 2016 Characterization of the GntR family regulator HpaR1 of the crucifer black rot pathogen Xanthomonas campestris pathovar campestris. Sci. Rep. 6:19862.

Swings, J. and Civetta, L. 1993. Xanthomonas. Springer, Dordrecht, The Netherlands.

Vorhölter, F. J., Schneiker, S., Goesmann, A., Krause, L., Bekel, T., Kaiser, O., Linke, B., Patschkowski, T., Rückert, C., Schmid, J., Sidhu, V. K., Sieber, V., Tauch, A., Watt, S. A., Weisshaar, B., Becker, A., Niehaus, K., and Pühler, A. 2008. The genome of Xanthomonas campestris pv. campestris $\mathrm{B} 100$ and its use for the reconstruction of metabolic pathways involved in xanthan biosynthesis. J. Biotechnol. 134:33-45.

Wang, F. F., Deng, C. Y., Cai, Z., Wang, T., Wang, L., Wang, X. Z., Chen, X. Y., Fang, R. X., and Qian, W. 2014. A three-component signalling system fine-tunes expression kinetics of HPPK responsible for folate synthesis by positive feedback loop during stress response of Xanthomonas campestris. Environ. Microbiol. 16:2126-2144.

Wang, L., Pan, Y., Yuan, Z. H., Zhang, H., Peng, B. Y., Wang, F. F., and Qian, W. 2016. Two-component signaling system VgrRS directly senses extracytoplasmic and intracellular iron to control bacterial adaptation under iron depleted stress. PLoS Pathog. 12:e1006133.

Wang, L., Zhang, L., Geng, Y., Xi, W., Fang, R., and Jia, Y. 2011. XerR, a negative regulator of $\mathrm{XccR}$ in Xanthomonas campestris pv. campestris, relieves its repressor function in planta. Cell Res. 21:1131-1142.

Wei, K., Tang, D. J., He, Y. Q., Feng, J. X., Jiang, B. L., Lu, G. T., Chen, B., and Tang, J. L. 2007. hpaR, a putative marR family transcriptional regulator, is positively controlled by $\mathrm{HrpG}$ and $\mathrm{HrpX}$ and involved in the pathogenesis, hypersensitive response, and extracellular protease production of Xanthomonas campestris pathovar campestris. J. Bacteriol. 189:2055-2062.

Wengelnik, K., Van den Ackerveken, G., and Bonas, U. 1996. HrpG, a key hrp regulatory protein of Xanthomonas campestris pv. vesicatoria is homologous to two-component response regulators. Mol. Plant-Microbe Interact. 9:704-712.

Zhang, Y., Liu, T., Meyer, C. A., Eeckhoute, J., Johnson, D. S., Bernstein, B. E., Nusbaum, C., Myers, R. M., Brown, M., Li, W., and Liu, X. S. 2008. Model-based analysis of ChIP-Seq (MACS). Genome Biol. 9:R137. 